\title{
Pemodelan Perubahan Garis Pantai Ujung Tape Kabupaten Pinrang
}

\author{
Irwan $^{1}$, Muhammad Ihsan ${ }^{2}$ \\ ${ }^{1}$ Prodi Teknik Kelautan Jurusan Teknologi Penangkapan Ikan Politeknik Pertanian Negeri Pangkajene Kepulauan, \\ ${ }^{2}$ Prodi Teknik Sipil, Sekolah Tinggi Teknik Baramuli, Pinrang
}

\begin{abstract}
Abstrak
Penelitian ini bertujuan untuk mengetahui magnitudo erosi dan sedimentasi garis pantai Ujung Tape dalam proyeksikan lima tahunan dan di mana letak bangunan pelindung pantai yang bisa diterapkan di lokasi tersebut. Metode penelitian yang digunakan adalah memodelkan gelombang dan garis pantai pada software STWAVE dan GENESIS yang berbasis model numerik. Kalibrasi model dilakukan dengan memodelkan garis pantai terukur (measured shoreline) dan garis pantai awal (initial shoreline) untuk mendapatkan koefisien kalibrasi (k1 dan k2). Nilai k1 dan k2 yang memiliki kesalahan error $(\varepsilon c)$ yang terkecil dan memiliki tren yang lebih mendekati perubahan garis pantai di lokasi digunakan sebagai variabel bebas terpilih untuk mensimulasikan garis pantai dalam lima tahun ke depan. Simulasi garis pantai juga dilakukan dengan penambahan model bangunan pelindung pantai yaitu pemecah gelombang (skenario A dan B). Hasil simulasi dari tahun pertama sampai tahun kelima menunjukkan garis pantai dominan mengalami erosi walaupun di beberapa grid mengalami sedimentasi. Sel grid ke 480 sampai 2640 mengalami erosi dimana yang terbesar adalah sel grid ke 1540 dengan erosi $-7331.99 \mathrm{~m} 3$. Perubahan garis Pantai Ujung Tape dari tahun pertama sampai tahun kelima menunjukkan pantai dominan mengalami erosi dengan volume angkutan sedimen sebesar $-462.863 \mathrm{~m} 3$. Bentuk perlindungan garis pantai Ujung Tape yang dapat mencegah erosi adalah melalui model breakwater skenario A dan B dengan tangkapan sedimen sebesar $509.583 \mathrm{~m} 3 /$ tahun (skenario A) dan $463.370 \mathrm{~m} 3 /$ tahun (skenario B).
\end{abstract}

Kata Kunci : angkutan sedimen, erosi, garis pantai, grid, kalibrasi.

\section{Pendahuluan}

Berkurangnya sumberdaya alam di daratan memungkinkan manusia untuk berusaha memanfaatkan sumberdaya di wilayah pesisir. Wilayah pesisir di jadikan sebagai salah satu pusat kegiatan manusia seperti wisata pantai, pemukiman, pembangunan jalan dan lain sebagainya. Pengeksploitasian sumberdaya pesisir menyebabkan terjadinya penurunan ekosistem pesisir menjadi tidak terkontrol. Eksploitasi yang berlebihan mengakibatkan rusaknya sarana dan prasarana pemukiman serta perubahan morfologi pantai (Setyandito dkk., 2007). Di satu sisi arus dan gelombang laut dapat menyebabkan erosi dan akresi (sedimentasi). Adanya proses akresi dan erosi yang berlangsung di daerah pantai menyebabkan terjadinya perubahan garis pantai yang cenderung mengikis sedikit demi sedikit daratan disekitar pantai. Hal ini tentunya berpengaruh langsung pada aktivitas manusia yang bermukim di sekitar pesisir pantai. Pengaruh itu dapat berupa semakin sempitnya lahan di sekitar pantai, terendamnya prasarana publik di pesisir pantai, dan terganggunya kegiatan wisata di sekitar pantai. Perubahan wilayah pesisir terutama garis yang mencakup perubahan penggunaan lahan maupun garis pantainya, dapat di ketahui melalui citra penginderaan jauh yang berupa hasil pemotretan Citra Satelit. Hasil analisis data penginderaan jauh dengan sistem informasi geografis dapat membaca berapa besar perubahan garis pantainya (Parman, 2010).

Corresponding author. Telp.: 085399068948

E-mail addresses: irwangani03@gmail.com
Dari beberapa hasil penelitian ditemukan bahwa perubahan garis pantai di Indonesia menunjukkan trend mundur dari garis pantai awal yang artinya telah mengalami abrasi. Sebagai contoh, Pantai Semarang Demak mengalami proses abrasi di beberapa tempat yang mencapai $0,5 \mathrm{~km}$ dari garis pantai awal sehingga menyebabkan hilangnya beberapa bagian kawasan tambak dan juga permukiman (Parman, 2010). Di daerah lain, di Kabupaten Pasaman Barat Provinsi Sumatera Barat, Pantai Sasak adalah pantai yang sering terkena abrasi akibat hantaman gelombang laut (Fajra, 2011). Simulasi model selama 19 tahun (1990-2008) di delta Sungai Jeneberang, Sulawesi Selatan menunjukkan tendensi adanya proses abrasi pada pantai yang berbentuk tonjolan akibat energi gelombang yang terfokuskan, sedangkan pantai melengkung mengalami sedimentasi akibat energi gelombang menyebar (Sakka dkk., 2011).

Pantai adalah suatu daerah di tepi perairan yang dipengaruhi oleh air pasang tertinggi dan air surut terendah. Daerah yang berada di sekitar pantai dinamakan pesisir, yakni suatu daerah darat di tepi laut yang masih mendapat pengaruh laut, seperti pasang surut, angin laut dan rembesan air laut. Pantai selalu menyesuaikan bentuk profilnya sedemikian sehingga mampu menghancurkan energi gelombang yang datangGaris pantai merupakan garis pertemuan antara pantai (daratan) dan air (lautan). Walaupun secara periodik permukaan air laut selalu berubah, suatu tinggi muka air tertentu 
yang tetap harus dipilih untuk menjelaskan posisi garis pantai (Muriadin, 2010). Analisa keseimbangan sedimen pantai dapat digunakan untuk mengevaluasi terjadinya erosi pada pantai. Perubahan garis pantai dapat diprediksi dengan membuat model matematik yang didasarkan pada imbangan sedimen pantai (Luhwahyudin dkk., 2012). Salah satu program alternatif untuk mensimulasikan perubahan garis pantai adalah GENESIS. Kegunaan model GENESIS adalah untuk mensimulasi transpor sedimen searah pantai yang disebabkan oleh energi gelombang. Program GENESIS menggambarkan posisi garis pantai pada awal simulasi dan posisi garis pantai setelah beberapa tahun simulasi dengan atau tanpa bangunan pelindung pantai. Program GENESIS dapat digunakan untuk memprediksi perubahan garis pantai, sehingga dapat ditentukan lokasi yang perlu penanganan dan juga jenis perlindungan pantainya (Pranoto, 2004).

GENESIS tidak mensimulasi perubahan profil pantai, menganggap bentuk profil pantai tetap dan hanya maju atau mundur, konsep ini di sebut perubahan model satu garis (one line model) karena bentuk garis tidak berubah hanya berpindah maju atau mundur. Sketsa definisi perubahan massa sedimen pada garis pantai dapat dilihat sebagai pada Gambar 1 beriku.
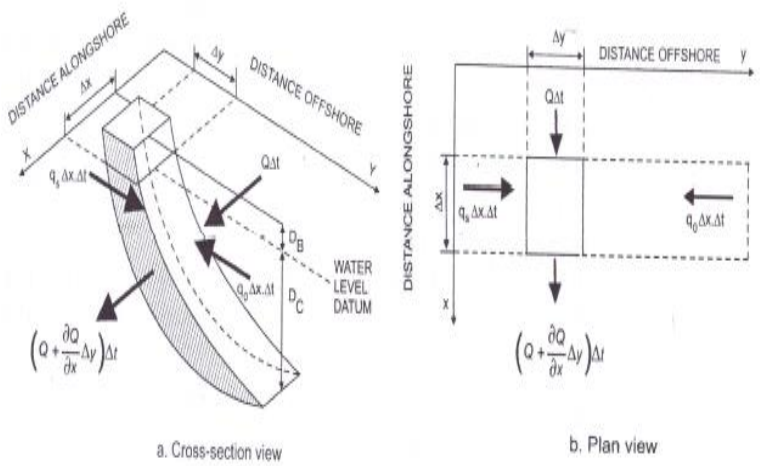

Gambar 1 Skema numerik perubahan massa sedimen.

Berdasarkan Gambar 1 di atas persamaan pengatur untuk laju ubah posisi garis pantai adalah:

$$
\frac{\partial y}{\partial t}+\frac{1}{D_{B}+D_{c}}\left(\frac{\partial Q}{\partial x}-q\right)=0
$$

Dimana:

$$
\begin{aligned}
& \mathrm{DB}= \text { berm height }(\mathrm{m}) \\
& \mathrm{Dc}= \text { closure depth }(\mathrm{m}) \\
& \mathrm{Y}= \text { jarak tegak lurus pantai }(\mathrm{m}) \\
& \mathrm{X}= \text { jarak searah pantai }(\mathrm{m}) \\
& \mathrm{Q}= \text { transport sedimen searah pantai } \\
&(\mathrm{m} 3 / \text { detik }) \\
& \mathrm{q}=\begin{array}{l}
\text { input/ out put sedimen dari luar } \\
(\mathrm{m} 3 / \text { detik) }
\end{array}
\end{aligned}
$$

GENESIS yang dipakai pada laporan ini adalah GENESIS yang terdapat pada suatu program bernama CEDAS (Coastal Engineering Design \& Analysis System) Versi 4.03. CEDAS adalah software yang terdiri dari beberapa jenis pilihan untuk menganalisis berbagai macam kasus yang berhubungan dengan pantai, sesuai dengan kebutuhan. Untuk dapat menggunakan GENESIS, sebelumnya harus melewati beberapa tahap terlebih dahulu, seperti Grid Generator, WWWL Data (Wind, Wave and Water Level Data), WISPH3, WSAV (Wave Station Analysis and Visualization), SPECGEN dan GENESIS.

Garis pantai Ujung Tape yang berlokasi 034'52.9" Lintang Selatan dan 119³0'55.9" Lintang Utara merupakan kawasan wisata dan pemukiman penduduk. Pesisir Pantai Ujung Tape sebagiannya telah dilengkapi dengan tanggul dan sebagiannya lagi belum. Pada posisi pantai yang tidak memiliki tanggul dipadati dengan pemukiman penduduk yang sangat dekat dengan garis pantai yakni sekitar 15 meter dari garis pantai. Mata pencaharian sebagian besar penduduknya adalah nelayan. Seiring dengan gelombang dan arus yang datang secara terus menerus tentu akan mengikis garis pantai dan hal ini akan mengancam keberadaan pemukiman penduduk nelayan. Berangkat dari hal tersebut, penulis tertarik untuk memprediksi perubahan garis pantai dan mensimulasikan posisi groin dan pemecah gelombang untuk mendapatkan perubahan garis pantai yang lebih stabil agar dapat melindungi pemukiman penduduk. Tujuan penelitian untuk mengetahui pola perubahan garis pantai dalam lima tahun serta lokasi yang mengalami erosi.

\section{Metode}

Penelitian ini merupakan penelitian berbasis komputasi dengan menggunakan software GENESIS yang terdapat pada suatu program bernama CEDAS (Coastal Engineering Design \& Analysis System) Versi 4.03 untuk mensimulasikan perubahan garis pantainya. Objek sekaligus lokasi penelitian adalah pantai Ujung Tape, Kelurahan Pallameang, Kabupaten Pinrang dengan koordinat 03\%47'52.9" Lintang Selatan dan 119 30'55.9" Lintang Utara. Panjang garis pantai yang ditinjau adalah 3540 meter, dengan titik awal di kampung nelayan di Kelurahan Pallameang pada koordinat UTM zone 51 $\mathrm{X}=779509 \mathrm{~m}, \mathrm{Y}=9575029 \mathrm{~m}$ dan berakhir pada pantai Ujung Tape dengan koordinat UTM X = $778677 \mathrm{~m}, \mathrm{Y}=9577614 \mathrm{~m}$.

Penelitian ini mensimulasikan perubahan garis pantai Ujung Tape selama lima tahun yaitu dari tahun 2012 sampai tahun 2017. Data yang diperlukan pada penelitian ini terdiri atas data primer dan sekunder. Data primernya adalah data 
karakteristik sedimen pantai yang berupa diameter rata-rata sedimen (d50) yang di ambil di tiga titik sepanjang garis pantai. Data sekunder terdiri atas data topografi-bathimetri, data pasang surut air laut, data kecepatan angin, data histori garis pantai. Data histori garis pantai adalah garis pantai yang didapatkan dari peta Rupa Bumi Indonesia (RBI) khusus layer garis pantai zona 51 pada tahun 2004. Garis pantai terukur adalah garis pantai yang didapatkan pada peta topografi batimetri hasil survey pada tahun 2012 .

Kalibrasi model ini dilakukan dengan memodelkan garis pantai terukur (measured shoreline) dan garis pantai awal (initial shoreline) untuk mendapatkan koefisien empiris (k1 dan k2). Nilai k1 dan k2 yang digunakan adalah nilai kalibrasi yang memiliki kesalahan error $(\mathcal{E})$ yang terkecil dan memiliki trend yang lebih mendekati perubahan garis pantai dilokasi. Setelah itu garis pantai tahun 2012 dapat diproyeksikan lima tahun berikut yakni sampai pada tahun 2017. Hasil ini memperlihatkan titik-titik atau grid garis pantai yang mengalami kerusakan. Kerusakan ini di analisis seberapa besar kerusakan serta lokasi kerusakannya. Kerusakan itu dicegah dengan memodelkan garis pantai dengan bangunan tambahan groin dan pemecah gelombang sebagai bangunan pelindung pantai dengan variasi jarak antar bangunan dan ukuran bangunan.

Kerusakan itu dicegah dengan memodelkan garis pantai dengan bangunan tambahan pemecah gelombang (detached breakwater). Breakwater skenario A ditempatkan pada sel grid ke 160 dan sel grid ke 420. Koefisien breakwater dianggap konstan dengan nilai koefisien 0,8 . Breakwater skenario $\mathrm{B}$ direncanakan 3 buah dengan posisi berada pada sel grid ke 160, 580 dan sel grid ke 1160.

Langkah - langkah menggunakan aplikasi GENESIS sebagai berikut :

1. Pertama diinput adalah grid generator atau penentuan batas area simulasi. Penentuan koordinat garis pantai terukur dan garis pantai awal di lokasi yang berada pada titik MSL. Selanjutnya dilakukan penginputan data gelombang signifikan.

2. Setelah simulasi gelombang berhasil dilakukan maka dilanjutkan dengan memasukkan parameter bangunan pantai eksisting dan kondisi batas (boundary condition) model. Bagian ini sangat penting karena data eksisting dan kondisi batas merupakan ciri atau karakter fenomena alam di lokasi penelitian sehingga nilai parameter yang dimasukkan harus mengacu pada hasil pengukuran di lapangan. Data eksisting itu diantaranya koordinat bangunan eksisting, ukuran bangunan pantai, laju sedimentasi dari sungai yang bermuara di lokasi dan kondisi batas model.

3. Setelah itu dilanjutkan dengan running model pantai eksisting pada sub program Genesis. Running model ini harus dilakukan beberapa kali untuk mengetahui hasil running yang sesuai atau mendekati histori perubahan garis pantai. Jika sudah didapatkan maka model inilah yang akan dijadikan model dasar untuk running selanjutnya.

4. Running selanjutnya menambahkan model bangunan pantai yang divariasikan posisinya. Jenis bangunan pantai yang akan dicoba adalah breakwater. Running ini akan diulang beberapa kali sampai mendapatkan perubahan garis pantai yang paling stabil.

\section{Hasil dan Pembahasan}

\subsection{Hasil Hasil Simulasi garis pantai dari tahun pertama sampai tahun kelima.}

Hasil simulasi menunjukkan bahwa pantai lebih dominan mengalami erosi walaupun di beberapa grid mengalami sedimentasi. Selama 5 tahun simulasi transport sedimen sebesar $-462.863 \mathrm{~m} 3$ yang sebagian besar terjadi di bagian selatan yaitu pantai di kelurahan Pallameang. Sel grid yang mengalami erosi terparah diantaranya sel grid ke 1540 dengan erosi sebesar $-7331 \mathrm{~m} 3$, sel grid ke 1520 dengan erosi $-7313 \mathrm{~m} 3$ dan sel grid 1560 dengan erosi $-7303 \mathrm{~m} 3$. Dengan memperhatikan mekanisme terjadinya erosi di sepanjang pantai Ujung Tape, erosi disebabkan adanya gelombang yang datang yang dominan dari arah barat laut yang kemudian pecah dan membawa sedimen pasir sepanjang pantai ke arah selatan lokasi penelitian. Hasil simulasi dari tahun pertama sampai tahun kelima dapat dilihat pada Gambar 2.

\subsection{Penanganan erosi dengan bangunan pemecah gelombang}

Dari hasil running/output model GENESIS diketahui bahwa perubahan volume transport sedimen selama 5 tahun dengan struktur pemecah gelombang skenario A adalah sebesar 2.547.913 m3, garis pantai dominan mengalami sedimentasi. Lokasi yang mengalami sedimentasi terbesar berada tepat dibelakang pemecah gelombang dengan laju sedimentasi sebesar $509.582 \mathrm{~m} 3 /$ tahun. Hasil simulasi pemecah gelombang skenario $\mathrm{B}$ menunjukkan perubahan volume transport sedimen selama 5 tahun yang juga mengalami sedimentasi sebesar +2.316.851 m3. Daerah dibelakang pemecah gelombang banyak mengendapkan sedimen dari arah utara dengan laju sedimentasi $463.370 \mathrm{~m} 3 /$ tahun. Gambar model pemecah 


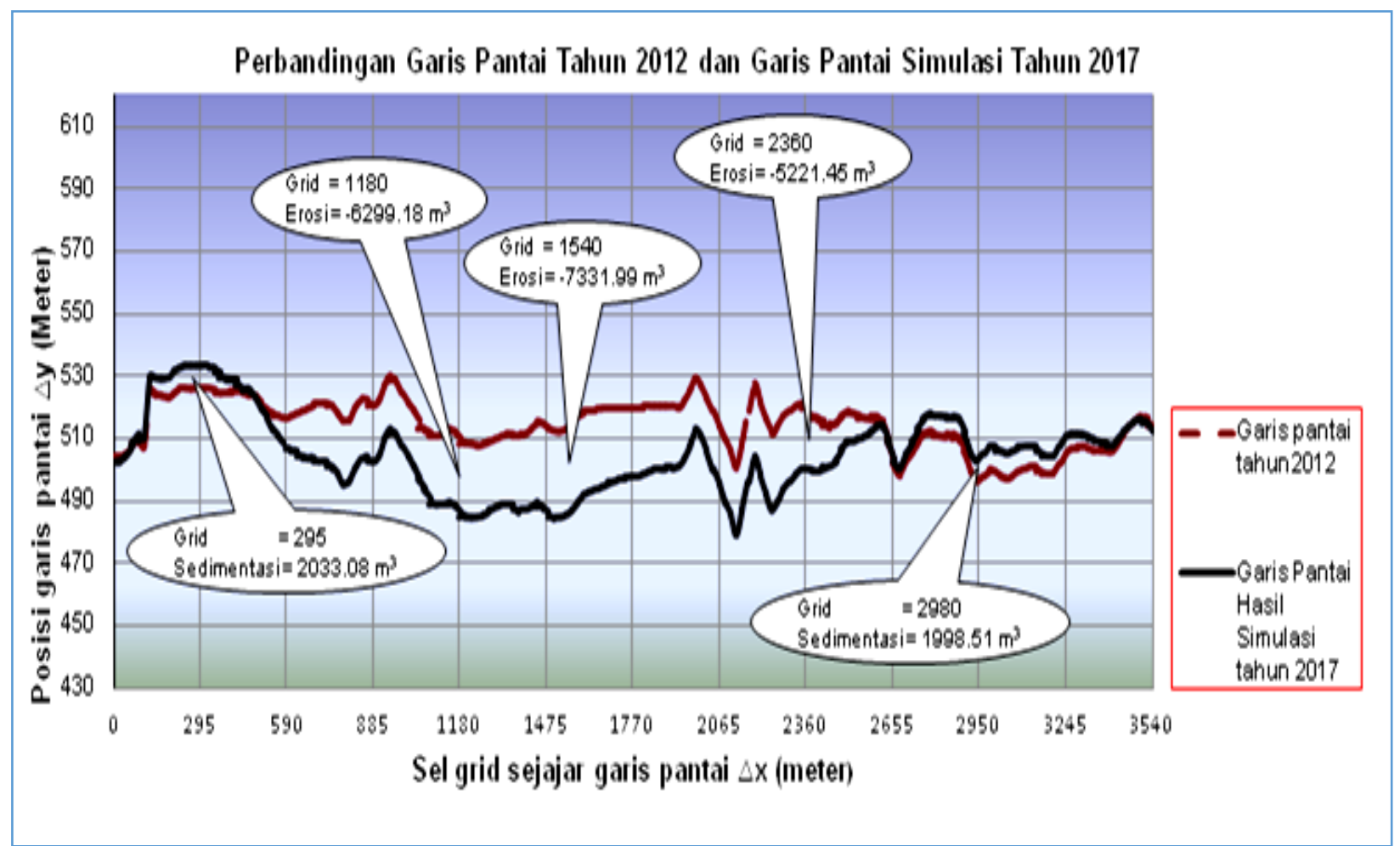

Gambar 2. Hasil running simulasi garis Pantai Ujung Tape dari tahun pertama sampai tahun kelima.

gelombang A dan B pada program GENESIS dapat dilihat pada lampiran 3 (gambar 3 dan 4).

\subsection{Pembahasan}

Penelitian ini menunjukkan bahwa sepanjang garis pantai Ujung Tape dan pantai di Kelurahan Pallameang dari tahun pertama sampai tahun kelima

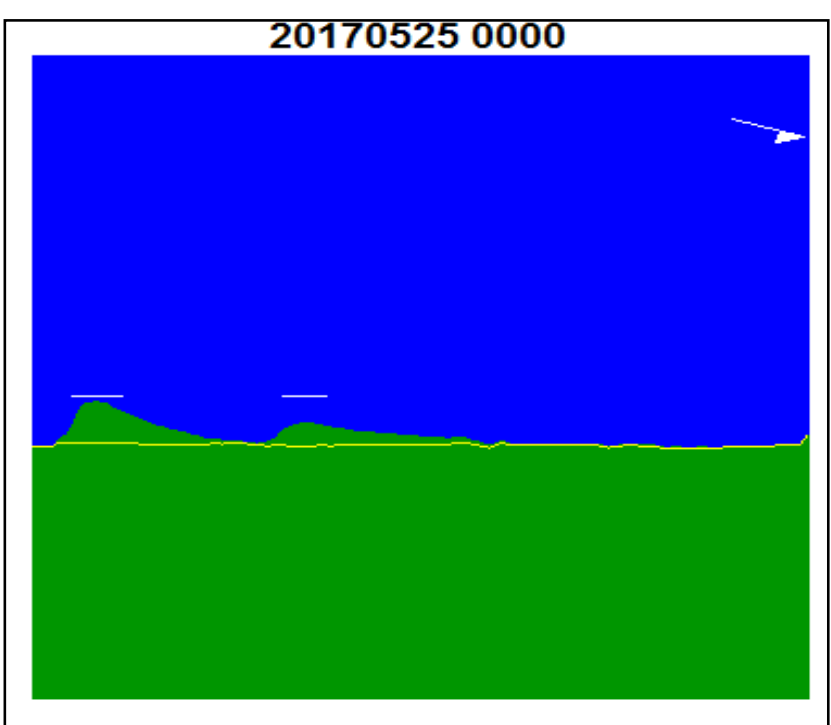

Gambar 3. Penempatan struktur pemecah gelombang seri pada program GENESIS dan hasil runningnya (model C).

diprediksi mengalami erosi. Hal ini disebabkan adanya gelombang datang dari arah barat laut yang kemudian pecah dan membawa sedimen pasir sepanjang pantai ke arah selatan lokasi penelitian. Hal ini terjadi karena gelombang biasanya mendekati pantai dengan kedudukan yang membentuk sudut terhadap garis pantai sehingga gelombang menjadi agen arus sejajar pantai (Poerbandono, 2004). Selain itu tinggi gelombang pecah dan lokasinya juga mempengaruhi besar transport sedimennya (Triatmadja, 2007). Daerah yang rawan mengalami erosi adalah pantai di kelurahan Pallameang yaitu dari grid ke 480 sampai 2640 .

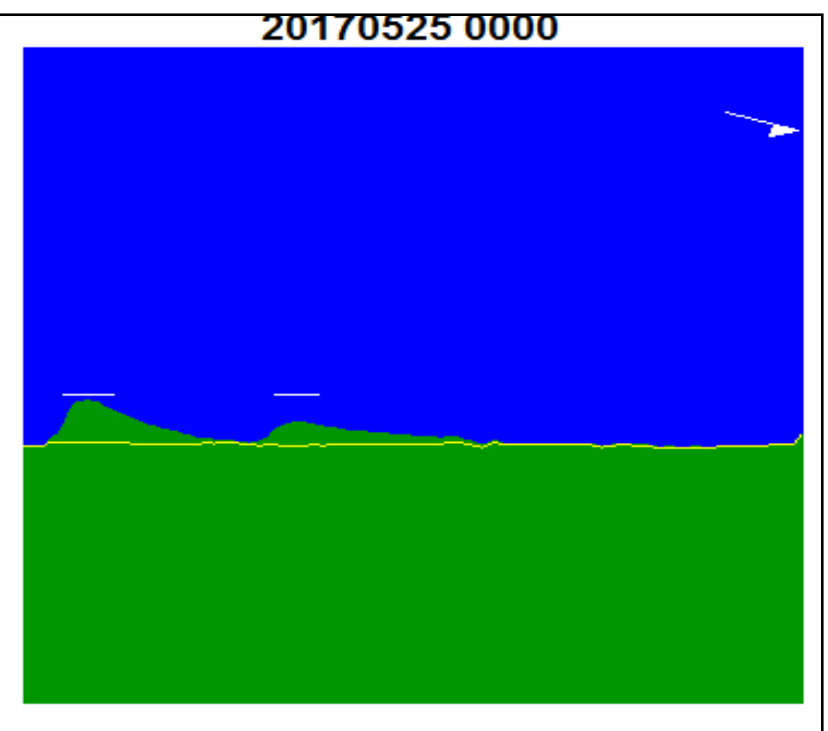

Gambar 4. Penempatan struktur pemecah gelombang seri pada Program GENESIS dan hasil runningnya (model D).

Penambahan model pemecah gelombang pada simulasi perubahan garis pantai menunjukkan terjadinya sedimentasi. Lokasi yang awalnya mengalami erosi dapat dipertahankan dengan struktur pemecah gelombang. Daerah di belakang pemecah gelombang mengendapkan sedimen yang 
terbawa dari arah utara Pantai Ujung Tape dan membentuk tombolo (skenario A dan B) pada 2017. Laju sedimentasi yang terjadi sebesar 509.582 m3/tahun (skenario A) dan $463.370 \mathrm{~m} 3 /$ tahun (skenario B). Tombolo yang terbentuk akan merintangi/menangkap transpor sedimen sepanjang pantai sehingga dapat berfungsi sebagai groin alami pada tahun-tahun selanjutnya.

\section{Kesimpulan}

Berdasarkan hasil penelitian yang telah dilakukan maka dapat diberikan beberapa kesimpulan sebagai berikut. Hasil simulasi perubahan garis Pantai Ujung Tape dari tahun 2012 sampai tahun 2017 menunjukkan pantai dominan mengalami erosi. Volume transpor sedimen sebesar -462.863 m3 dengan rata-rata laju transport sedimen sebesar $92.572 \mathrm{~m} 3 /$ tahun. Hasil filterisasi gelombang pada sub program STWAVE dan WISPH3 menunjukkan angkutan sedimen di sepanjang Pantai Pallameang dan pantai Ujung Tape disebabkan oleh gelombang yang datang dari arah barat laut. Gelombang inilah yang secara kontinu menggerus garis pantai Ujung Tape. Bentuk perlindungan garis Pantai Ujung Tape yang dapat mencegah erosi adalah model breakwater skenario A dan B. Skenario ini menempatkan bangunan breakwater sistem seri 2 sampai 3 breakwater pada daerah yang mengalami erosi. Hasil model menunjukkan garis pantai dapat kembali akibat sedimentasi sebesar $509.583 \mathrm{~m} 3 /$ tahun (skenario A) dan $463.370 \mathrm{~m} 3 /$ tahun (skenario B).

\section{DAFTAR PUSTAKA}

Fajra M. (2011). Simulasi Numeris Perubahan Garis Pantai Sasak Akibat Pembangunan Groin.Padang. Jurnal Teknik Sipil Universitas Andalas.

Luhwahyudin M,dkk. (2012). Analisa Perubahan Garis Pantai Tegal dengan Menggunakan Empirical Orthogonal Function (EOF). Jurnal Teknik ITS, Vol 1.Surabaya

Muriadin. (2010). Pengaruh Pembangunan Pelabuhan Waren Kabupaten Waropen Terhadap Perubahan Garis Pantai. Tesis. Yogyakarta.

Parman S. (2010). Deteksi Perubahan Garis Pantai Melalui Citra Penginderaan Jauh Di Pantai Utara Semarang Demak. Jurnal Jurusan Geografi Fisika UNNES,Vol 7,No.1.Semarang

Poerbandono. (2004).Pemecah Ombak Timbulkan Masalah Baru.PR Cyber Media ITB.Bandung

Pranoto S. (2004).Prediksi Perubahan Garis Pantai Menggunakan Model GENESIS. Jurnal FT UNDIP Vol 13 Juli 2007.Semarang

Sakka dkk. (2008). Studi Perubahan Garis Pantai Di Delta Sungai Jeneberang Makassar.Jurnal Ilmu danTeknologi Kelautan Tropis Fakultas
Perikanan dan Ilmu Kelautan IPB Vol 3,No.2.Bogor

Setyandito O dkk. ( 2007). Analisa Erosi Dan Perubahan Garis Pantai Pada Pantai Pasir

Buatan Dan Sekitarnya Di Takisung, Propinsi Kalimantan Selatan. Jurnal Teknik Sipil Fakultas Teknik Universitas Mataram,Vol 7,No.3.Mataram

Triatmadja R. (2007)). Pengantar Teknik Pantai. Diktat Kuliah S2 FT UGM.Yogyakarta.

Triatmodjo B. (1999). Teknik Pantai. Beta Offset. Yogyakarta. 